\title{
НАДЕЖНОСТЬ КАК ПЛАТФОРМА ДЛЯ РАЗВИТИЯ. ОРГАНИЗАЦИОННЫЕ И ТЕХНИЧЕСКИЕ МЕРЫ ПОВЫШЕНИЯ НАДЕЖНОСТИ ПРИ ЭКСПЛУАТАЦИИ СЕЙСМИЧЕСКИХ РЕГИСТРАТОРОВ «ЕРМАК-5» НА РАЗЛИЧНЫХ ОБЪЕКТАХ МОНИТОРИНГА
}

\author{
П.Г. БУТЫРИН \\ Горный институт УрО РАН, г. Пермь
}

\begin{abstract}
Аннотация. В статье приведены основные методы контроля и повышения надежности работы сейсмических регистраторов на примере «Ермак-5». Разработанные мероприятия основаны на двухлетнем опыте и могут быть использованы для приборов аналогичной функциональности и назначения. Кроме того, опыт эксплуатации стал основой для функциональной и эргономической модернизации.
\end{abstract}

Ключевые слова: сейсмический регистратор, надежность автономных приборов, автономная сейсмическая станция, сторожевой таймер, умножитель частоты, жизненный цикл приборов.

Напряженно-деформированное состояние породного массива оценивается комплексом геофизических методов, среди которых сейсмологический мониторинг выполняется в режиме, близком к реальному времени. Это становится возможным благодаря повсеместному использованию современных цифровых систем сбора и обработки данных [1], где основными элементами являются цифровые сейсмические регистраторы «Ермак-5», разработанные в «ГИ УрО РАН».

На данный момент регистраторы «Ермак-5» применяются на следующих объектах мониторинга:

1) территория г. Березники (БКПРУ-1) - 14 регистраторов [2];

2) территория г. Соликамск (СКРУ-2) - 4 регистратора [2];

3) сейсмологический мониторинг зоны Краснослободского разлома РУ-2 ОАО «Беларуськалий» (Республика Беларусь) [3] - 4 регистратора;

4) при проведении полевых исследований применяются 5 регистраторов.

Таким образом, всего в постоянной работе находится 27 регистраторов.

Эксплуатация такого количества приборов, зачастую на труднодоступных объектах, предъявляет все более строгие требования к надежности. Формально меры повышения надежности можно разделить на организационные и технические.

\section{Организационные меры повышения надежности}

1. Создание ремонтной базы для быстрой замены неисправных приборов и их компонентов.

2. Обеспечение регулярного сбора и анализа диагностической информации о всех используемых приборах.

3. Ведение журналов жизненного цикла приборов для всех установленных и выпускаемых приборов. Каждый регистратор имеет уникальный заводской номер, зависящий от идентификатора процессора. Этот номер является ключевым при записи сведений о регистраторе и событий в базу данных при эксплуатации.

4. Обеспечение своевременного обновления аппаратно-программных средств для устранения выявленных сбойных фрагментов микропрограммы. После выпуска очередной версии микропрограммы производится тестирование на стендовых образцах, где в первую очередь проверяются исправленные ветви алгоритма. Далее следует тестирование на легкодоступных объектах мониторинга с низким уровнем 
критичности. После успешного тестирования всех необходимых режимов работы производится обновление микропрограмм на всех используемых регистраторах. Для оперативного обновления микропрограммы предусмотрены два основных механизма:

1) обновление с карты памяти, куда записываются двоичные файлы-имиджи микропрограммы;

2) обновление средствами удаленного доступа; при этом для проверки целостности переданных файлов используется механизм проверки контрольной суммы, что гарантирует запись в память процессора требуемого файла микропрограммы.

В июле 2019 г. была введена в строй система автоматизированного сбора диагностической информации о состоянии регистраторов. Системные параметры раз в 10 минут поступают в систему сбора и сохраняются в файловой базе данных. Возможен анализ первичной информации из файлов-журналов, а также подготовлен инструмент для визуального анализа диагностических данных. Например, анализ записей значений температуры и коррекции таймера высокого разрешения позволяет определить зависимость частоты тактового генератора от температуры. Введение поправочных механизмов в дальнейшем может увеличить точность хода часов в случае длительной автономной работы регистратора.

\section{Технические меры повышения надежности}

В результате почти двухгодичной эксплуатации большого числа регистраторов [4] были определены узлы с наибольшим числом сбоев:

1) съемный носитель информации;

2) драйвер файловой системы, приводящий к зависанию центрального процессора;

3) умножитель частоты тактового генератора.

В качестве съемного носителя информации в регистраторе применяется карта памяти типа micro-SD в индустриальном исполнении с требуемым рабочим температурным диапазоном, устойчивая к механическим воздействиям и электромагнитному излучению. Кроме того, предусмотрены технические средства для диагностики сбоев карты памяти и файловой системы, а также средства для восстановления после сбоев:

1) в случае сбоя или отказа файловой системы информация сохраняется в системном журнале, а прибор автоматически перезапускается;

2) если при запуске не удается подключить карту памяти, регистратор переходит в режим работы без карты памяти, при этом доступно управление файловой системой для сохранения доступных данных, в критических случаях возможно форматирование карты памяти; после форматирования автоматически создаются рабочие директории и конфигурационный файл.

Аппаратные сбои - беда многих сложных процессорных систем. Разработчиками центрального процессора «Ермак-5» предусмотрены несколько подсистем для выхода из состояния «зависания».

1. Специальные системные вызовы, возникающие в случае отсутствия отклика от критически важных узлов процессора.

2. Сторожевой таймер «WatchDog»- подсистема, вызывающая аппаратный перезапуск процессора через определенный период времени (в нашем случае 16 сек, рис. 1). Эта подсистема использует отдельный внутренний генератор и не зависит от успешного запуска основного тактового генератора процессора. Чтобы избежать регулярных аварийных сбросов, приложение должно сбрасывать счетчик сторожевого таймера чаще, чем 1 раз в 16 секунд. Такая процедура встроена в работу секундного генератора. Таким образом, счетчик сбрасывается каждую секунду. Такая схема защищает нас только от очень редких аппаратных зависаний, но не позволяет избежать аварийных остановов при операциях с 
файловой системой. Особенности реализации функций работы с файловой системой указывают на непрогнозируемое увеличение длины одной операции, например, открытия файла (до 300 сек), что не дает использовать сброс аппаратного сторожевого таймера в основном цикле приложения. Для исключения зависания, вызываемого сбоем файловых операций, используется «Long time WatchDog» - программный сторожевой таймер с периодом переполнения и сброса 900 сек.

3. В конструкции регистратора предусмотрено использование в качестве тактового генератора специального устройства на основе кварцевого резонатора с частотой 25 МГц. При запуске приложения внутри процессора включается умножитель, и рабочая частота доводится до 43 МГц. Дважды в процессе эксплуатации наблюдался сбой при запуске умножителя частоты, что приводило к полному останову регистратора, из которого прибор можно вывести только перезапуском. Использование включения и блокировки сторожевого таймера при включении питания дает возможность выполнить аппаратный сброс регистратора через 16 секунд, если умножитель частоты не запустится.

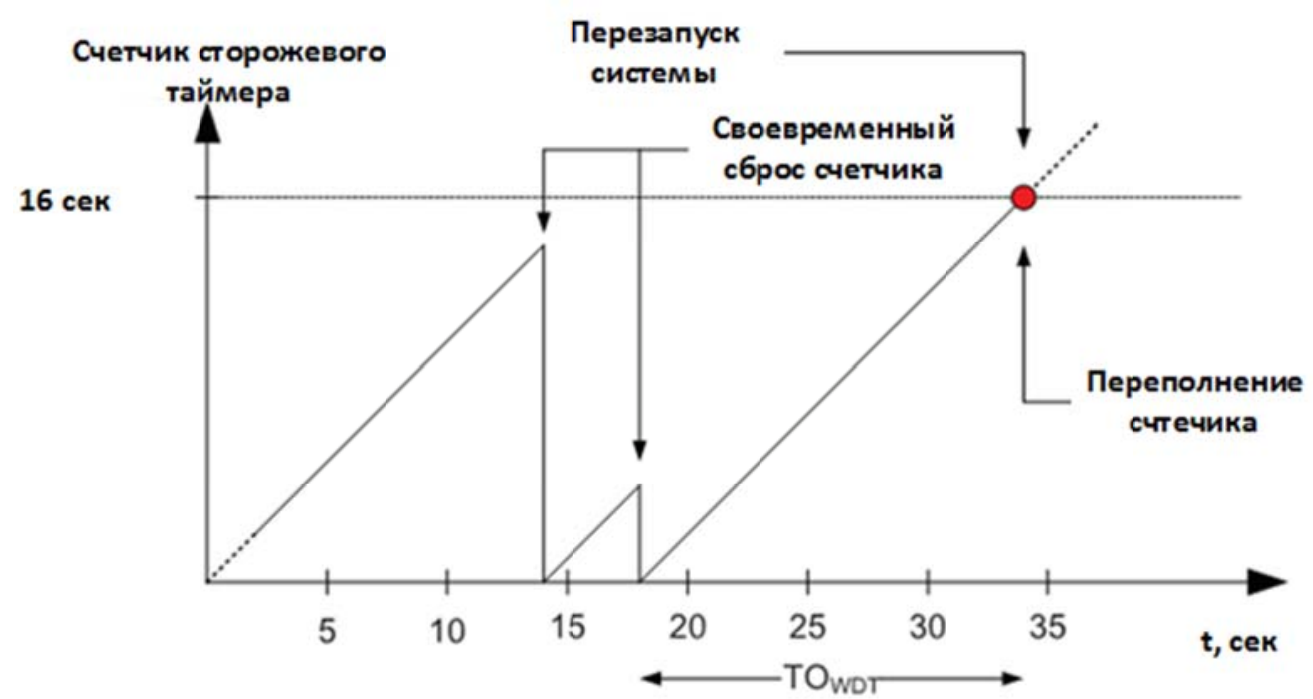

Рис. 1. Принцип работы «Сторожевого таймера WatvhDog»

Регистраторы на труднодоступных объектах дополнительно оснащены внешними таймерными реле - устройствами, которые раз в двое суток выполняют выключение и включение регистратора, таким образом тестируя работу файловой системы на чувствительность к внеплановым отключениям питания, и увеличивая вероятность успешного запуска в случае критических сбоев.

В планы по развитию проекта включены:

1) увеличение числа каналов;

2) уменьшение уровня внутреннего шума регистратора за счет использования аналого-цифровых преобразователей нового поколения;

3) подготовка модуля подключения к беспроводным сетям;

4) подготовка приложения оперативного управления для мобильных устройств.

Реализация вышеперечисленных планов может быть осуществлена на надежной и отказоустойчивой аппаратно-программной платформе, однако множество случайных сбоев могут быть выявлены только при длительном тестировании, как на стенде, так и на реальных объектах мониторинга. Комплекс вышеперечисленных мероприятий и инструментов позволяет успешно эксплуатировать и тестировать все регистраторы, производить корректировку после сбоев и своевременно обновлять микропрограммы в случае обнаружения критических тупиковых ветвей алгоритма приложения. 


\title{
БИБЛИОГРАФИЧЕСКИЙ СПИСОК
}

1. Butyrin P.G., Verkholantsev F.G., Verkholantsev A.V., Shulakov D.Y. Digital Seismic Logger "Ermak-5". Experience of Development and Implementation // Seismic Instruments. - 2019. - Vol. 55, № 2. - P. 117 128. DOI: $10.3103 / \mathrm{S} 0747923919020051$.

2. Шулаков Д. Ю., Бутырин П. Г., Верхоланцев А. В. Сейсмологический мониторинг Верхнекамского месторождения: задачи, проблемы, решения // Горн. журн. - 2018. - № 6. - С. 25-29. DOI: 10.17580/gzh.2018.06.05

3. Дягилев Р.А., Богдан С.И., Барбиков Д.В. Влияние подземной разработки калийного месторождения на активность секущих тектонических нарушений // Развитие систем сейсмологического и геофизического мониторинга природных и техногенных процессов на территории Северной Евразии: материалы Междунар. конф., посвященной 50-летию открытия Центральной геофизической обсерватории в г. Обнинске / отв. ред. А.А. Маловичко; ФИЦ ЕГС РАН. - Обнинск, 2017. - С. 30.

4. Butyrin P., Shulakov D., Verkholantsev P., Verkholantsev A., Kichigin M. Seismic recorder "Ermak-5" as the part of the system of seismological monitoring of Verkhnekamskoe potash deposit // International Multidisciplinary Scientific GeoConference Surveying Geology and Mining Ecology Management, SGEM: $18^{\text {th }}$ International Multidisciplinary Scientific Geoconference, SGEM 2018, Bulgaria, 2-8 july. - Albena, 2018. - V. 18, № 1.1. - P. 963-970. DOI: 10.5593/sgem2018/1.1/S05.120

\section{РУДНИЧНАЯ АЭРОГАЗОДИНАМИКА И ГОРНАЯ ТЕПЛОФИЗИКА}

УДК 622.416

DOI: $10.7242 /$ echo.2019.1.16

\section{РАБОТА ДВИГАТЕЛЕЙ ВНУТРЕННЕГО СГОРАНИЯ В РУДНИКАХ}

\author{
Н.И. АЛЫМЕНКО \\ Горный институт УрО РАН, г. Пермь
}

\begin{abstract}
Аннотация: В статье рассмотрена работа машин с двигателями внутреннего сгорания (ДВС) на разных рудниках и в разные годы. Для снижения концентрации вредных компонентов в отработавших газах предложен и испытан нейтрализатор эжекторного типа. В результате испытаний эжекторного нейтрализатора на технологическом автотранспорте получено снижение концентрации вредных веществ в отработавших газах. Установлено, что температура отработавших газов недостаточна для эффективной работы каталитического нейтрализатора. При движении отработавших газов по горной выработке концентрация вредных компонентов в них снижается. Было предложено рассчитывать количество воздуха по фактору «выхлопные газы ДВС», исходя из фактической их концентрации.
\end{abstract}

Ключевые слова: горная выработка, двигатель внутреннего сгорания (ДВС), отработавшие газы, выхлопы ДВС, эжекторный нейтрализатор, каталитический нейтрализатор.

\section{Введение}

Множество разнообразных способов решения задач по снижению токсичности отработавших газов можно разделить на ряд групп, объединенных общими признаками.

К первой группе отнесем наиболее перспективные, связанные с качеством используемого топлива.

Ко второй отнесем меры, предпринимаемые перед выбросом уже из выпускной системы автомобиля, т.е. перед выбросом в атмосферу.

B третью группу мер следует выделить конструктивные усовершенствования, которыми могут снабжаться автомобили на стадии производства. 